\title{
Successful pulmonary arterial embolization followed by curative surgery for a lepidic predominant lung adenocarcinoma with severe hypoxemia
}

Louise Sebane ${ }^{1}$, Mostafa El-Hajjam ${ }^{2}$, Philippe Puyo ${ }^{3}$, Elisabeth Longchampt ${ }^{4}$ and Etienne Giroux Leprieur ${ }^{1,5^{*}}$ (D)

\begin{abstract}
Background: Lepidic predominant adenocarcinoma is characterized by frequent refractory hypoxemia due to intrapulmonary shunting. Severe hypoxemia can induce perioperative complications in case of thoracic surgery.
\end{abstract}

Case presentation: We report a case of a 67 year-old woman with localized lepidic adenocarcinoma in the right lower lobe with severe hypoxemia. A selective arterial lung embolization allowed an instantaneous correction of the hypoxemia, and a curative lobectomy was safely performed 1 week after without any complication. The staging was PT3NOMO, and the patient received adjuvant chemotherapy.

Conclusions: This is the first case-report of successful endovascular embolization before curative surgery for a lepidic predominant lung adenocarcinoma.

Keywords: Thoracic surgery, Non-small cell lung cancer, Lepidic adenocarcinoma, Hypoxemia, Arterial embolization

\section{Background}

Adenocarcinoma is the most frequent histological subtype in non-small cell lung cancer (NSCLC). Lepidic predominant subtype is a particular form of invasive lung adenocarcinoma, developed initially from Club cells and/or type II pneumocytes [1]. The alveolar spreading induces a specific clinical and radiological presentation, with dyspnea, cough, ground-glass attenuations and alveolar consolidations on CT-scan [1]. The presence of severe hypoxemia represents an issue in case of localized tumour with indication of surgical resection. We present here the case of a 67 year-old women with localized lepidic predominant adenocarcinoma and severe hypoxemia due to intrapulmonary shunting, who was successfully treated by pulmonary arterio-embolization followed by curative lower lobe resection.

\footnotetext{
* Correspondence: etienne.giroux-leprieur@aphp.fr

${ }^{1}$ Department of Respiratory Diseases and Thoracic Oncology, APHP -

Ambroise Pare Hospital, 9 Avenue Charles de Gaulle, 92100

Boulogne-Billancourt, France

${ }^{5}$ EA4340, UVSQ, Paris-Saclay University, Boulogne-Billancourt, France

Full list of author information is available at the end of the article
}

\section{Case presentation}

A 67 year-old woman was admitted to the Department of Respiratory Diseases and Thoracic Oncology for dyspnea, increasing over a few weeks, without infectious context. Her medical history was a breast cancer in 2006 treated by surgery, chemotherapy and radiotherapy, without evidence of recurrence, diabetes, systemic hypertension and an active smoking at 40 packet-years. The oxygen saturation at the admission was at $80 \%$ in room air, with need for supplementation of oxygen at $6 \mathrm{l} / \mathrm{min}$. Arterial blood gas on $6 \mathrm{l} / \mathrm{min} \mathrm{O} 2$ supplementation showed a PO2 of $70 \mathrm{mmHg}$, a PCO2 of $39 \mathrm{mmHg}$ and $\mathrm{pH}$ of 7.42. Functional tests showed a moderate obstructive syndrome, with a forced expiratory volume in $1 \mathrm{sec}$ (FEV1) on vital capacity ratio at $66 \%$, and a FEV1 at $1350 \mathrm{ml}(62 \%)$. Unfortunately, the evaluation of diffusing capacity of the lung for carbon monoxide (DLCO) was not feasible at the time of the diagnosis, due to the severity of dyspnea. The CT-scan revealed ground-glass opacities and alveolar consolidation in the right lower lobe (Fig. 1). Transthoracic echocardiography demonstrated normal left ventricular 


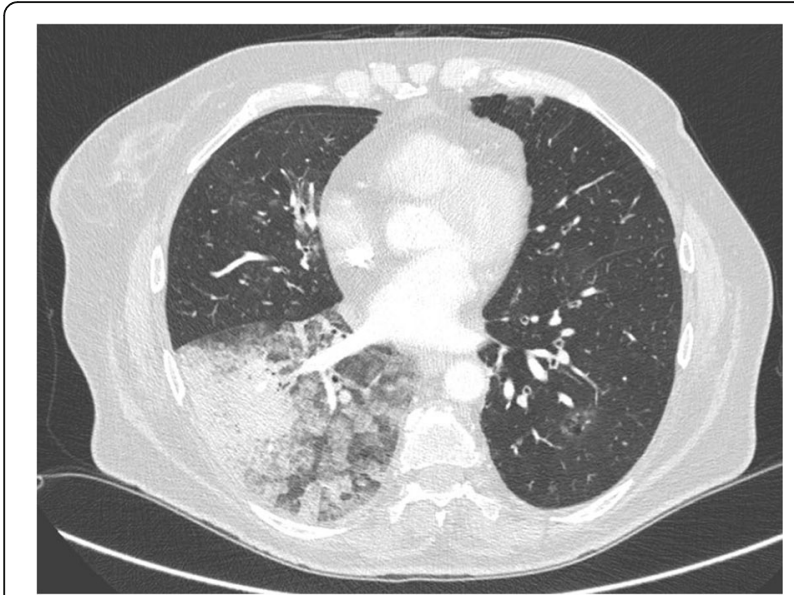

Fig. 1 CT-scan showing ground-glass opacities and alveolar consolidation in the right lower lobe

ejection fraction. Cytology on bronchial aspiration and right lower lobe transbronchial biopsy found adenocarcinomatous cells with positive staining for Thyroid Transcription Factor-1 (TTF-1) in immunohistochemistry (IHC). Brain CT-scan was normal, and PET-CT showed localized hypermetabolism on the right lower lobe. A pulmonary angiography was performed. The temporary balloon occlusion of the right lower pulmonary artery showed a rapid increase of the oxygen rate from $90 \%$ on oxygen $6 \mathrm{~L} / \mathrm{mn}$ to $100 \%$ in room air, and the patient underwent thereafter an intravascular occlusion of this artery by coils and plugs (Fig. 2). The oxygen saturation increased instantly to $100 \%$ at room air; arterial blood gas at room air showed a PO2 of $82 \mathrm{mmHg}$, a $\mathrm{PCO} 2$ of $33 \mathrm{mmHg}$ and a $\mathrm{pH}$ of 7.43. One week later, a lower right lobectomy with mediastinal lymphadenectomy was performed without postoperative complication. The pathological study showed a $9 \mathrm{~cm}$-sized lepidic predominant adenocarcinoma (pT3N0M0), with necrotic and hemorrhagic changes due to the embolization, and Cytokeratin 7 (CK7) and TTF-1 positive IHC staining. The patient received adjuvant cisplatin and vinorelbine chemotherapy.

\section{Discussion and conclusion}

The deep hypoxemia observed occasionally in lepidic lung adenocarcinoma is due to the filling of alveolar spaces by tumor cells, along with normal perfusion of these territories. This phenomenon induces a venoarterial shunting, with hypoxemia and normocapnia. The first description was made in 1969 by Wolinsky and Williams, with a case of diffuse bronchio-alveolar lung adenocarcinoma showing hypoxemia, normal lung angiogram and normal pulmonary function tests [2]. Since then, only a few cases of lepidic adenocarcinoma treated by surgery have been reported [3-10]. The

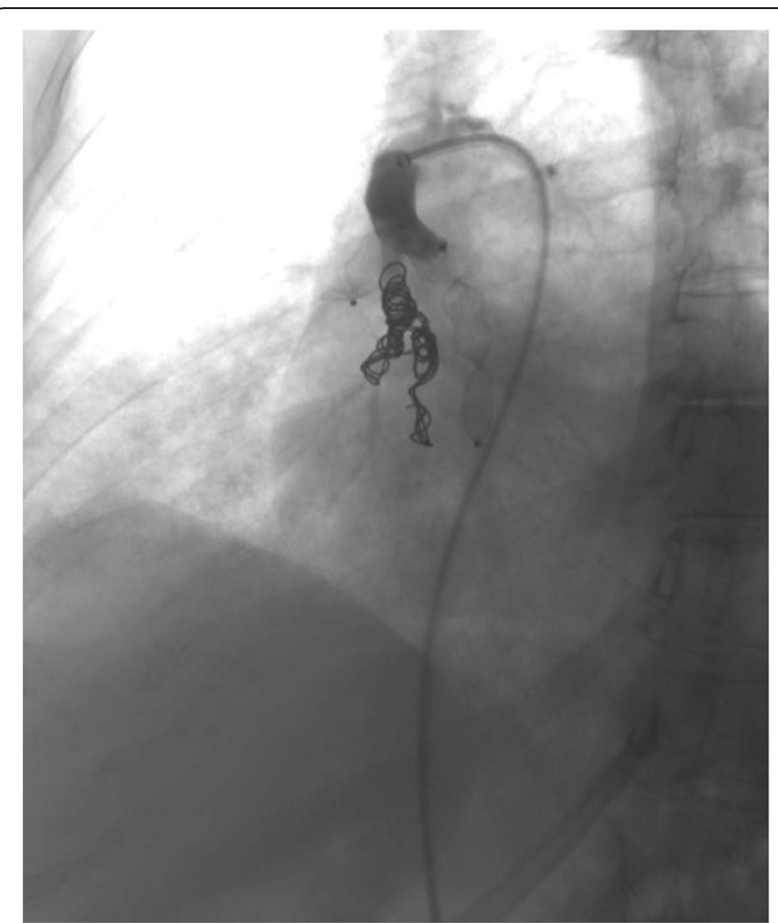

Fig. 2 Successful intravascular occlusion of the right lower lung artery by coils and plugs

surgery induced an improvement of hypoxemia and symptoms in all patients, with an overall survival after surgery between 21 days and 24 months in such a palliative context. However, the management of the hypoxemia due to intrapulmonary shunting with perfusion of a non-ventilated lobe, is not codified. The possibility of surgical ligation of the vessels in the lower lobe during the thoracotomy was considered for our patient, but we chose to correct the deep hypoxemia before the surgery, as deep hypoxemia can be a source of complications during the perioperative time, and is reported to be a prognostic factor [11-13].

The temporary balloon occlusion is a good indicator of the potential benefit of surgery or embolization. Wartzki et al. described a case of left pneumonectomy for a stage III adenocarcinoma performed after a temporary balloon occlusion showing a correction of the shunting [8]. One case of palliative embolization was reported, in 2015 [9]. In this case of an extensive bilateral lung disease, the procedure failed to demonstrate a PO2 improvement but it induced a clear improvement of the dyspnea. Finally, the association of the two procedures (embolization then surgery) has only been reported in one case [10]. It was also a palliative situation and the association of these two procedures allowed an improvement of the dyspnea and the PO2.

Our case is the first to describe the successful presurgical management of a lepidic predominant 
adenocarcinoma with a curative objective. The occlusion of the right lower lung artery allowed in our patient a rapid and prolonged improvement of the haematosis with a complete correction of the hypoxemia. The surgery was then performed safely with optimal respiratory conditions and without any complication.

In conclusion, the occlusion of the right to left shunt by endovascular embolization is a safe and efficient procedure before curative surgery for lepidic predominant lung adenocarcinoma.

\section{Abbreviations}

CK7: Cytokeratin 7; CT-scan: Computerized-tomography scan; DLCO: Diffusing capacity of the lung for carbon monoxide; FEV1: Forced expiratory volume in one second; IHC: Immunohistochemistry; NSCLC: Non-small cell lung cancer; TTF1: Thyroid Transcription Factor-1

\section{Acknowledgements}

There is nothing to be acknowledged.

\section{Funding}

For this study no funding exists.

\section{Availability of data and materials}

The data supporting our thesis is completely available in this article. Articles referred to can be found in the reference list.

\section{Authors' contributions}

LS and EGL collected the data; EGL supervised the work; MEH made the arterial embolization; PP made the surgery; EL made the pathological analyses; all authors reviewed the manuscript. All authors read and approved the final version of the manuscript.

\section{Authors' information}

Not applicable.

\section{Ethics approval and consent to participate}

Written informed consent was obtained from the patient for publication of this Case report and any accompanying images. A copy of the written consent is available for review.

This case report study was carried out respecting the Declaration of Helsinki in its current version. Ethical approval: not applicable.

\section{Consent for publication}

Written informed consent was obtained from the patient for publication of this Case report and any accompanying images.

\section{Competing interests}

The authors declare that they have no competing interests.

\section{Publisher's Note}

Springer Nature remains neutral with regard to jurisdictional claims in published maps and institutional affiliations.

\footnotetext{
Author details

'Department of Respiratory Diseases and Thoracic Oncology, APHP Ambroise Pare Hospital, 9 Avenue Charles de Gaulle, 92100 Boulogne-Billancourt, France. ${ }^{2}$ Department of Radiology, APHP - Ambroise Pare Hospital, Boulogne-Billancourt, France. ${ }^{3}$ Department of Thoracic Surgery, Foch Hospital, Suresnes, France. ${ }^{4}$ Department of Pathology, Foch Hospital, Suresnes, France. ${ }^{5}$ EA4340, UVSQ, Paris-Saclay University, Boulogne-Billancourt, France.
}

Received: 20 December 2017 Accepted: 28 March 2018

Published online: 10 April 2018

\section{References}

1. Travis WD, Brambilla E, Noguchi M, et al. International association for the study of lung cancer/american thoracic society/european respiratory society international multidisciplinary classification of lung adenocarcinoma. J Thorac Oncol. 2011;6:244-85.

2. Wolinsky $H$, Lin A, Williams MH Jr. Lung perfusion in bronchiolo-alveolar carcinoma. A case report. Am Rev Respir Dis. 1969;99:585-9.

3. Barlesi F, Doddoli C, Thomas P, Kleisbauer JP, Giudicelli R, Fuentes P. Bilateral bronchioloalveolar lung carcinoma: is there a place for palliative pneumonectomy? Eur J Cardiothorac Surg. 2001;20(6):1113-6.

4. Chetty KG, Dick C, McGovern J, Conroy RM, Mahutte CK. Refractory hypoxemia due to intrapulmonary shunting associated with bronchioloalveolar carcinoma. Chest. 1997;111(4):1120-1.

5. Falcoz PE, Hoan NT, Le Pimpec-Barthes F, Riquet M. Severe hypoxemia due to intrapulmonary shunting requiring surgery for bronchioloalveolar carcinoma. Ann Thorac Surg. 2009:88(1):287-8.

6. Fishman HC, Danon J, Koopot N, Langston HT, Sharp JT. Massive intrapulmonary venoarterial shunting in alveolar cell carcinoma. A case report. Am Rev Respir Dis. 1974;109(1):124-8.

7. Sarlin RF, Schillaci RF, Georges TN, Wilcox JR. Focal increased lung perfusion and intrapulmonary veno-arterial shunting in bronchiolo-alveolar cell carcinoma. Am J Med. 1980;68(4):618-23.

8. Wartski M, Zerbib E, Regnard JF, Herve P. Reverse ventilation-perfusion mismatch in lung Cancer suggests intrapulmonary functional shunting. J Nucl Med. 1998;39:1986-9.

9. Tan JYA, Walters DL, Poon K, Zimmerman P, Aldons P. Palliative embolisation for intrapulmonary shunting in lepidic predominant adenocarcinoma of the lung. Respir Med Case Rep. 2015;15:121-4.

10. Crossno PF, Milstone AP, Lambright ES, Carbone DP, Light RW. Severe intrapulmonary shunting in bronchioloalveolar cell carcinoma corrected by selective pulmonary artery occlusion and palliative tumor resection. Chest. 2006;130(4Meetingabstracts):313S-c-314S.

11. Brunelli A, Kim AW, Berger Kl, Addrizzo-Harris DJ. Physiologic evaluation of the patient with lung cancer being considered for resectional surgery: diagnosis and management of lung cancer, 3rd ed: American College of Chest Physicians evidence-based clinical practice guidelines. Chest. 2013; 143(5 Suppl):e166S-90S

12. Celli BR. What is the value of preoperative pulmonary function testing? Med Clin North Am. 1993:77(2):309-25.

13. Zibrak JD, O'Donnell CR, Marton K. Indications for pulmonary function testing. Ann Intern Med. 1990;112(10):763-71.

Submit your next manuscript to BioMed Central and we will help you at every step:

- We accept pre-submission inquiries

- Our selector tool helps you to find the most relevant journal

- We provide round the clock customer support

- Convenient online submission

- Thorough peer review

- Inclusion in PubMed and all major indexing services

- Maximum visibility for your research

Submit your manuscript at www.biomedcentral.com/submit
) BioMed Central 